\title{
PLURILINGUISMO: PRÁTICAS LINGUÍSTICAS DE IMIGRANTES BRASILEIROS NO SURINAME
}

\section{PLURILINGUALISM: LANGUAGE PRACTICES OF BRAZILIAN IMMIGRANTS IN SURINAME}

\author{
Monica Maria Guimarães Savedra ${ }^{1}$, Gabriel Mendes Hernandez Perez ${ }^{2}$
}

\begin{abstract}
RESUMO: O trabalho apresentado propõe uma reflexão sobre as práticas linguísticas dos imigrantes brasileiros no Suriname, antiga colonia holandesa comumente descrita como um mosaico cultural e linguístico. Entendendo o plurilinguismo como um fenômeno dinâmico, que apresenta diferentes estágios ao longo da vida dos falantes e recorrendo a estudos recentes sobre os usos linguísticos de surinameses em idade escolar, apresentamos uma discussão, com base ainda em dados colhidos in loco, sobre os usos que os brasileiros fazem de sua L1 e dos idiomas mais usados no Suriname: o holandês - único com status de oficiale o sranantongo - crioulo de base inglesa que serve como língua de contato no país.
\end{abstract}

PALAVRAS-CHAVE: Plurilinguismo; Suriname; Sranantongo; Imigrantes Brasileiros.

ABSTRACT: This paper proposes a reflection on the language use of Brazilian immigrants in Suriname, the former Dutch colony commonly described as a cultural and linguistic mosaic. Based on recent research on school-age Surinameses' language use and on fieldgathered data, the authors, regarding plurilingualism as a dynamic condition, one that presents different stages throughout speakers' lives, attempt a better understanding of the immigrants' language use concerning Portuguese and the most used languages in Suriname: Dutch - the only one with official status - and the English-based creole Sranantongo, which serves as contact language in the country.

KEYWORDS: Plurilingualism; Suriname; Sranantongo; Brazilian Immigrants.

\section{Introdução}

\footnotetext{
${ }^{1}$ Doutora em Linguística pela UFRJ. Professora adjunta na UFF.

${ }^{2}$ Mestre em Estudos da Linguagem pela UFF. Professor de alemão como língua estrangeira no Colégio Cruzeiro-RJ.
} 
Os estudos desenvolvidos em contato linguístico vêm nas últimas décadas se empenhando em desconstruir o mito do monolinguismo que idealiza a combinação "um povo, um país, uma língua". Porém, no caso do Suriname em particular, até mesmo leigos hão de se espantar com o mosaico linguístico observado no pequeno país com cerca de 540.000 habitantes de etnias distintas, como por exemplo, os descendentes de indianos, africanos, javaneses e chineses e onde coexistem cerca de 20 línguas, entre elas o holandês - único idioma com status de oficial - e o sranantongo, crioulo de base inglesa que possui função de língua de contato no país.

Adicionando novos contornos à paisagem multiétnica e multilíngue surinamesa encontra-se a recente onda migratória brasileira que começou a ser percebida em meados dos anos 80 . Estima-se que atualmente vivam no país cerca de $16.000^{3}$ brasileiros, compondo $3 \%$ da população do Suriname. Na capital Paramaribo, os imigrantes, muitos deles indivíduos de baixa escolaridade originários do Pará e Maranhão, concentram-se sobretudo na parte norte da cidade, onde reconfiguraram a paisagem urbana local com seus comércios identificados por letreiros em português, suas músicas e suas bandeiras.

O presente trabalho é parte da pesquisa de mestrado de Perez (2017) sobre gênero, práticas e representações linguísticas dos brasileiros vivendo na antiga colônia holandesa e propõe um diálogo entre as pesquisas recentes de Fierens (2004) e Léglise \& Migge (2015) sobre os usos e competências linguísticas de jovens surinameses e os dados colhidos in loco pelo autor, entendendo o plurilinguismo como um fenômeno relativo e que apresenta diferentes estágios ao longo das vidas dos falantes.

\section{Plurilinguismo, multilinguismo, bilinguismo e afins: uma breve discussão terminológica}

O estudo de situações de plurilinguismo tem como primeiro obstáculo a questão terminológica. Ainda que as definições e critérios para classificação de indivíduos como monolíngues e bi/multilingues não sejam consensuais entre os teóricos, o senso comum tende a considerar como característica desses fenômenos "a competência total em duas línguas" equivalente à do falante nativo, conforme a definição proposta por Bloomfield ([1933] 1984) e já bastante questionada desde a segunda metade do século XX.

\footnotetext{
${ }^{3}$ Estimativa fornecida em julho de 2015 por José Paulo Ribeiro, presidente da Fundação para o Desenvolvimento Brasileiro no Suriname (Fundação BRASUR).
} 
Para além do impasse concernindo a definição das características que descreveriam o sujeito bi/multilíngue, há também a problemática dos próprios binômios bi/multilinguismo e bi/plurilinguismo, usados frequentemente de maneira indistinta, ainda que alguns autores proponham a diferenciação entre multilinguismo e plurilinguismo ${ }^{4}$. O Quadro Europeu Comum de Referência, influente documento publicado pela União Europeia em 2001 e que estabelece diretrizes para a descrição dos níveis de competência linguística para o aprendizado e ensino de línguas, define como multilinguismo a coexistência ou conhecimento de diferentes línguas em uma dada sociedade, enquanto que o plurilinguismo, por sua vez, seria a competência comunicativa possuída pelo indivíduo em mais de um idioma.

Entendemos ser bastante arbitrária a escolha dos termos multi/plurilinguismo como caracterizadores de um fenômeno social e individual, respectivamente, e adotaremos aqui, para fins de maior clareza, apenas os conceitos de plurilinguismo social e plurilinguismo individual, conforme comentados por Wei (2013) e Edwards (2013). Assim como Mackey (2013), consideramos ainda as variáveis do plurilinguismo meras extensões numéricas daquelas do bilinguismo, razão pela qual não será feita neste estudo a distinção entre essas duas condições, empregando-se o termo plurilinguismo para definir a coexistência, contato e interação de duas ou mais línguas.

Já para caracterizar e melhor entender o plurilinguismo individual, recorremos aos conceitos de bilinguismo e bilingualidade propostos por Savedra (2009), que entende o domínio de duas formas linguísticas como fenômenos dinâmicos que passam por diferentes estágios ao longo da vida dos falantes. A autora define o bilinguismo:

\footnotetext{
"como a situação em que coexistem duas línguas como meio de comunicação num determinado espaço social, ou seja, um estado situacionalmente compartimentalizado de uso de duas línguas. Bilingualidade representa os diferentes estágios de bilinguismo, pelos quais os indivíduos, portadores da condição de bilíngue, passam na sua trajetória de vida" (SAVEDRA, ibid grifo da autora)
}

A condição de bilíngue, que entendemos aqui como análoga à de plurilíngue, deve ser, segundo a autora, analisada conforme o contexto e a idade de aquisição das línguas e pelos seus usos funcionais variados, ou seja, o uso linguístico em diferentes situações interacionais, como o ambiente familiar, social (amigos, vizinhos), escolar e profissional. Savedra lembra ainda que o emprego de uma língua em detrimento de outra em dada situação não é uma

\footnotetext{
${ }^{4}$ Publicações em línguas germânicas como o alemão e o holandês, por exemplo, não costumam adotar tal distinção, referindo-se a ambos os conceitos pelos termos únicos Mehrsprachigkeit e meertaligheid, respectivamente.
} 
condição constante e varia no decorrer da vida do indivíduo, sendo essa escolha condicionada, como o próprio plurilinguismo em si, a fatores sociais e comportamentais como família, grupo social, escolaridade e ocupações profissionais, que podem levar à manutenção ou ao abandono de determinada língua.

\section{Pesquisas recentes sobre os usos linguísticos no Suriname}

Estudos sobre o panorama sociolinguístico surinamês realizados pouco após a independência do país, como o de Campbell (1983) e Carew (1982) ainda descreviam o holandês como uma língua de acesso restrito às elites do país. Campbell, que atribuía ao idioma dos antigos colonizadores a característica de "mercadoria de luxo no mercado linguístico do Suriname", comentava ainda que os esforços in vitro para tornar o holandês a língua de fato do país não haviam surtido efeito e que, "apesar do método de imersão na língua praticado nas escolas, os alunos pouco familiarizados com o holandês não conseguem dominá-lo perfeitamente." Carew, por sua vez, observava que as classes mais desfavorecidas socialmente possuíam um domínio limitado no idioma que lhes permitia apenas interagir nos papéis sociais a eles restritos, pois "uma vez que suas rendas os mantêm confinados a esses espaços, a necessidade de proficiência no holandês fica reduzida." Ainda com relação às práticas linguísticas, Carew pontuava que o uso do idioma oficial e do sranantongo eram tão claramente definidos que o emprego indevido de um ou outro culminaria no rompimento de todo um conjunto de tradições sociais e linguísticas.

As constatações acima expostas, embasadas em observações realizadas há mais de três décadas, nos sugerem um modelo de diglossia em nível nacional, porém sem um plurilinguismo generalizado, cenário que Fishman (1967) descrevia como comum entre comunidades recentemente urbanizadas.

Mais tarde, Fishman (1980 apud ROMAINE, 1995) nos lembra que nas sociedades contemporâneas a compartimentalização entre a forma linguística de prestígio e as populares (High and Low varieties) não possui mais caráter estanque, uma vez que ela sofre a influência de fenômenos cada vez mais presentes atualmente, como a mobilidade, urbanização, fluidez dos papéis sociais e permeabilidade das redes sociais. De fato, Ferguson ([1959] 1972) já apontava alguns desses fatores como capazes de desestabilizar o caráter diglóssico de uma comunidade de fala. Ao observar a condição diglóssica de países caribenhos, nos quais uma 
língua crioula coexiste com uma língua dominante europeia, Devonish (2008) afirma que a pressão da forma de prestígio em direção aos domínios privados e informais é um cenário comum atualmente, ocasionado em grande parte pelo desejo dos pais de que seus filhos aprendam a língua oficial com o objetivo de melhorar suas chances de ascensão social.

Trabalhos mais recentes sobre as práticas e representações linguísticas desenvolvidos no Suriname na última década, como o de Léglise \& Migge (2015) e Fierens (2006), apontam para algumas mudanças no perfil sociolinguístico surinamês com relação aos estudos de 30 anos atrás, sobretudo com relação às competências e usos funcionais reservados ao holandês e ao sranantongo.

A pesquisa de Léglise \& Migge (2015), realizada com base em observações no Suriname e em entrevistas conduzidas em escolas da capital e do interior do país com cerca de 3.000 alunos do ensino fundamental surinamês, chegou a conclusões que apontam para um plurilinguismo individual generalizado, pelo menos entre crianças que frequentam as escolas no país. Apenas $1 \%$ dos entrevistados afirmou falar somente uma língua, sendo que $65 \%$ alegaram possuir competência em três ou mais idiomas. $63 \%$ das crianças, um número surpreendente, declarou ser o holandês sua primeira língua, fato que as autoras acreditam ser uma sobrevalorização da parte dos informantes, decorrente do contexto no qual a pesquisa foi realizada. O sranantongo, por sua vez, foi declarado como primeira língua por apenas $6 \%$ dos indivíduos, apesar de fazer parte do repertório de $79 \%$ deles. Ainda que possa se contar com uma possível distorção dos dados fornecidos pelos falantes, as estatísticas reunidas apontam para um declínio do uso do sranantongo no ambiente familiar, fenômeno que as autoras explicam como sendo consequência do estigma atribuído à língua até os anos 80 e que levou muitos pais a adotarem o holandês como meio de comunicação dentro de suas casas com o objetivo de oferecerem melhores chances acadêmicas e profissionais aos seus filhos.

O sranantongo, geralmente junto com o holandês, constataram Léglise e Migge, continua sendo usado em uma vasta gama de situações, como no contato com avós, irmãos e amigos, sendo que tais usos variam conforme a região do país estudada. Os meninos, afirmam as autoras, são mais propensos a recorrer ao sranantongo do que as meninas devido aos estigmas associados à língua, fato já observado em Perez (2015).

Conforme as entrevistas, observou-se ainda que as línguas do país, de maneira geral, nem sempre se encontram restritas a usos funcionais específicos, como a comunicação com a família, amigos, na escola etc. Apesar de muitos informantes haverem declarado que a 
escolha do idioma varia conforme a situação interacional, um grande número de crianças afirmou usar o holandês em vários contextos comunicativos ou, ainda, usar mais de uma língua na mesma interação, sendo os pares mais frequentes a língua de seus respectivos grupos étnicos em conjunto com o holandês ou com o sranantongo (em menor proporção).

Com base em suas observações no país, Léglise \& Migge (2015) concluem que, apesar do plurilinguismo individual observado no Suriname, os padrões de uso linguístico são bastante estratificados. Em contraste com as populações rurais, que fazem uso mais generalizado de seus idiomas locais, como o sarnami e as línguas dos povos quilombolas, as famílias urbanas de classe média dão preferência ao holandês para a comunicação com os filhos, recorrendo a outras línguas, como o sranantongo, para insultar e em caso de brigas. Já nas famílias mais carentes da capital, adicionam as autoras, muitos pais com competência limitada no holandês se dirigem aos filhos em sranantongo ou em outra língua minoritária, mas exigem de seus filhos o uso do idioma oficial em casa, sendo tal imposição mais forte sobre as meninas, devido às conotações negativas do sranantongo que, conforme os valores locais, "não condizem com a imagem de moças respeitáveis." De fato, o holandês ainda é bastante associado à polidez, pois conforme afirmam Diepeveen \& Hüning (2016) e Léglise \& Migge (2015), não é considerado adequado dirigir-se em outra língua que não a oficial a desconhecidos, pessoas mais velhas ou caso se deseje causar uma boa primeira impressão, como no caso de flertes.

O estudo de Fierens (2006), embasado em entrevistas com cerca 200 adolescentes de diversas classes sociais matriculados no ensino médio de escolas de Paramaribo, auferiu resultados bastante alinhados aos de Léglise \& Migge (2015). 79\% dos informantes, uma quantidade também impressionante, afirmou ser o holandês a língua (ou uma das línguas) usada(s) na comunicação com a família. O sranantongo apresentou números mais modestos: apenas 20\%. No tocante à competência linguística, 96\% dos entrevistados declararam-se competentes em holandês e $62 \%$ em sranantongo. Igualmente surpreendente foi o fato de $82 \%$ dos jovens terem alegado interagir em holandês mais de $50 \%$ do tempo ao longo de uma semana, enquanto que o sranantongo seria usado com frequência igual ou inferior a $30 \%$.

No comércio de bairro os jovens afirmaram usar o holandês com pouca frequência. Por outro lado, as perguntas do tipo "É estranho ver alguém falando holandês na cantina da escola?", "Você fala holandês com os colegas de escola fora das aulas?" apresentaram respostas bastante favoráveis ao holandês. 
Os resultados da pesquisa de Fierens (2006) aqui reproduzidos devem ser analisados levando em consideração primeiramente que o grupo entrevistado consistia de 151 moças e 39 rapazes e, em segundo lugar, que as práticas linguísticas, sobretudo no caso de jovens, podem variar bastante de acordo com o sexo/gênero do indivíduo, conforme já comentamos. É importante destacar ainda que as estatísticas de ambos os estudos citados se embasam em dados fornecidos apenas por jovens escolarizados. Entretanto, tendo em vista a alta taxa de escolaridade surinamesa, que conta com mais de $90 \%$ de suas crianças e adolescentes matriculados em escolas do país, os trabalhos de Léglise \& Migge (2015) e Fierens (2005), ainda que não reflitam o perfil sociolinguístico do Suriname como um todo, são de grande valia e apontam tendências interessantes.

O plurilinguismo social e individual é uma realidade inegável atualmente no Suriname, condicionada a fatores extralinguísticos como local de residência, grupo étnico, classe social, sexo/gênero e idade. A crescente urbanização do país, o aumento das taxas de escolaridade e de mobilidade social e geográfica observados no país nos últimos 20 anos garantiram urna maior exposição e acesso ao holandês. As interações monolíngues tornam-se cada vez menos evidentes no Suriname e já são atualmente associadas a estilos antiquados de vida, dando lugar aos não raros fenômenos de alternância de código linguístico, conforme observam Léglise \& Migge (2015). Ainda que o sranantongo, apesar de seus estigmas, tenha ganhado importância como símbolo de resistência e identidade nacional no período pósindependência e venha se fazendo notar em discursos políticos, campanhas públicas e nas artes em geral, o holandês, conforme vimos, não mais pode ser classificado como a língua das elites, reservada a situações comunicativas mais formais. A língua oficial, sobretudo na capital e entre os jovens, desempenha papel fundamental nas vidas sociais dos surinameses e, concluem Léglise \& Migge, está disponível e sendo usada por praticamente todos, ainda que não das mesmas maneiras.

\section{Usos linguísticos de imigrantes brasileiros no Suriname: resultados da pesquisa em campo}

Apresentamos nesta parte do trabalho alguns dados relativos aos usos linguísticos de imigrantes brasileiros vivendo há pelo menos dois anos no Suriname, obtidos através de observação e de 22 entrevistas semiestruturadas realizadas na capital Paramaribo em julho de 2015. As conversas se basearam em um questionário contendo 59 perguntas, através das quais 
procurou-se obter, entre outros, os dados demográficos dos falantes, informações sobre a aquisição e competência linguísticas e os usos funcionais das línguas.

Com relação aos fatores extralinguísticos de escolaridade e sexo, os falantes se distribuíam da seguinte forma:

\begin{tabular}{|l|l|c|c|}
\hline \multicolumn{1}{|l|}{ Sexo/gênero } & masculino & feminino \\
\hline Escolaridade & $\begin{array}{l}\text { Ensino fundamental } \\
\text { (completo e incompleto) }\end{array}$ & 4 & 4 \\
\cline { 2 - 4 } & $\begin{array}{l}\text { Ensino médio } \\
\text { (completo e incompleto) }\end{array}$ & 4 & 4 \\
\cline { 2 - 4 } & $\begin{array}{l}\text { Ensino superior } \\
\text { (completo e incompleto) }\end{array}$ & 3 & 3 \\
\hline
\end{tabular}

Tabela 1: Relação dos entrevistados conforme escolaridade e sexo/gênero

O recorte realizado não pretendeu refletir o perfil sociolinguístico da comunidade de brasileiros vivendo no país, mas tão somente analisar as práticas linguísticas dos imigrantes, considerando as variáveis de sexo/gênero e escolaridade.

Para fazer referência específica aos falantes, utilizamos um sistema alfanumérico de siglas, no qual a primeira letra "H" ou "M" indicará o sexo e os dois dígitos seguintes, a idade.

Primeiramente procurou-se saber como os falantes avaliavam suas competências linguísticas em português, L1 de todos os entrevistados, em inglês ${ }^{5}$, holandês e sranantongo. Enquanto a maioria dos entrevistados avaliou o domínio do português como muito bom, os resultados referentes às línguas mais usadas no Suriname apresentaram a seguinte tendência:

\begin{tabular}{|c|c|c|c|c|c|c|}
\hline \multicolumn{7}{|c|}{ Holandês } \\
\hline \multirow{2}{*}{$\begin{array}{l}\text { Competência } \\
\text { linguística }\end{array}$} & \multicolumn{3}{|c|}{ Escolaridade (completo e incompleto) } & \multicolumn{2}{|c|}{ Sexo/gênero } & \multirow{2}{*}{ Total } \\
\hline & Sup. & Méd. & Fund. & $\mathrm{F}$ & M & \\
\hline Muito bom & 4 & 2 & 0 & 3 & 3 & 6 \\
\hline Regular & 1 & 2 & 2 & 2 & 3 & 5 \\
\hline Pouco & 1 & 3 & 3 & 5 & 2 & 7 \\
\hline Nada & 0 & 1 & 3 & 1 & 3 & 4 \\
\hline \multicolumn{7}{|c|}{ Sranantongo } \\
\hline \multirow{2}{*}{$\begin{array}{l}\text { Competência } \\
\text { linguística }\end{array}$} & \multicolumn{3}{|c|}{ Escolaridade (completo e incompleto) } & \multicolumn{2}{|c|}{ Sexo/gênero } & \multirow{2}{*}{ Total } \\
\hline & Sup. & Méd. & Fund. & $\mathrm{F}$ & M & \\
\hline Muito bom & 3 & 4 & 1 & 3 & 5 & 8 \\
\hline
\end{tabular}

\footnotetext{
${ }^{5}$ Apesar de não ser a língua oficial do Suriname, o inglês foi incluído entre as opções de resposta devido à sabida importância da qual o idioma goza no cenário globalizado atual. No caso do Suriname especificamente, a língua tem especial relevância cultural e econômica: O inglês é o idioma oficial da vizinha Guiana e da maioria dos países membros da CARICOM, bloco de cooperação política e econômica do qual o Suriname faz parte desde 1995. Além disso, é na língua inglesa que se veicula, algumas vezes sem legendas, grande parte da programação televisiva do país.
} 


\begin{tabular}{|l|l|l|l|l|l|l|}
\hline Regular & 2 & 1 & 4 & 5 & 2 & 7 \\
\hline Pouco & 0 & 0 & 3 & 0 & 3 & 3 \\
\hline Nada & 1 & 2 & 1 & 3 & 1 & $\mathbf{4}$ \\
\hline
\end{tabular}

Tabela 3: Competência linguística em holandês e sranantongo conforme escolaridade e sexo/gênero dos falantes

Observamos que falantes com menor escolaridade possuem, de maneira geral, um domínio bastante limitado do holandês, uma vez que, dos 8 falantes com ensino fundamental, 6 afirmaram falar pouco ou nada da língua. Entre os falantes com ensino superior percebe-se urna tendência inversa, com 4 dos 6 entrevistados que se encaixam nesse perfil avaliando seu domínio de holandês como muito bom. No caso dos falantes com ensino médio as competências linguísticas se distribuem de maneira mais ou menos uniforme, mas cabe aqui, entretanto, uma constatação interessante: Os dois entrevistados com ensino médio que se declararam muito competentes no holandês e os dois interlocutores com ensino fundamental que admitiram possuir competência regular no idioma são os jovens M20, H19, H16 e M15 e tratam-se dos únicos jovens abordados pela pesquisa que concluíram ou estão atualmente frequentando escolas surinamesas.

Cruzando a variável escolaridade com a competência em sranantongo, observamos que o somatório das declarações "muito bom" e "regular" se distribui de maneira exatamente uniforme entre os três níveis de ensino. Ao comparar a competência entre as duas línguas analisadas possuída pelos entrevistados com ensino fundamental, percebe-se que o sranantongo é uma língua mais acessível aos indivíduos de baixa escolaridade.

A análise do sexo/gênero dos falantes também revela algumas tendências interessantes. Vemos que, enquanto três homens admitiram não dominar a língua oficial do país em absoluto, apenas uma mulher fez a mesma declaração. Curiosamente, o sranantongo apresenta um quadro exatamente oposto, o que sugere, senão uma real falta de competência linguística, pelo menos a relutância ou propensão de algumas imigrantes em admitir qualquer nível de proficiência em sranantongo ou holandês respectivamente. Observamos ainda, que as três brasileiras que se declararam nada competentes na língua não oficial são, além das jovens M20 e M15 já citadas anteriormente, a imigrante M45, que possui ensino superior completo e alto grau de domínio do holandês.

A verificação da variável acima, embora não forneça resultados que permitam apontar qual língua é mais falada por homens ou mulheres de maneira geral, sugere que indivíduos do sexo/gênero masculino adquirem uma maior competência no sranantongo em comparação 
com as mulheres. Os depoimentos que reproduzimos abaixo nos fornecem urna visão não só das práticas linguísticas dos imigrantes, mas também de algumas de suas representações.

H30: Eu falo o sranan... porque, assim, deixa eu te explicar uma coisa... Entre homem, eu tenho que conversar o sranatongo... Se eu tiver conversando uma conversa formal, coisa de negócios, ai eu já tenho que mudar naturalmente o tom pro holandês... Agora, se a gente tá aqui, brincando, entre amigos, e tiver conversando em holandês contigo, os cara já vão olhar pra gente (e dizer) "ih, dois viadinho e tal".

E: E o sranan a senhora diria que é muito bom, dá pra se comunicar?

M47: É, mas não é muito correto uma mulher em Suriname ficar falando taki-taki ${ }^{6}$ (...) É muito vulgar.

E: Aí se a senhora vai falar com alguém na rua...

M47: Eu misturo holandês com taki-taki.

Salientamos ainda que dentre os indivíduos abordados pela pesquisa, avaliaram-se como pouco competentes nas duas línguas mais usadas no Suriname apenas os sujeitos H40 e $\mathrm{H} 25$, ambos funcionários de estabelecimentos localizados no norte da capital e voltados para o público brasileiro. O primeiro informante imigrou há 2 anos e trata-se do entrevistando com menor tempo de residência no país. H40, que atua como técnico em uma rádio, declarou ainda possuir conhecimentos regulares de inglês. Já o jovem H25 reside há 5 anos no Suriname, possui ensino fundamental incompleto e trabalha como garçom.

A despeito das declarações de alguns entrevistados que afirmaram conhecer imigrantes que se comunicavam apenas em português e de algumas observações em campo, nas quais pude testemunhar alguns imigrantes com problemas de comunicação no comércio local, o número de indivíduos que se consideram monolíngues apresentou-se pouco expressivo no universo da amostragem, lembrando mais uma vez que essa não pretendeu ser um reflexo do perfil da comunidade de brasileiros vivendo no país.

Os entrevistados foram perguntados também acerca do contexto de aquisição das línguas. Percebeu-se que a imensa maioria dos que se declararam regularmente ou muito competentes em holandês frequentaram escolas surinamesas ou tiverem aulas particulares do idioma. O sranantongo, por sua vez, é adquirido predominantemente sem instrução formal.

As duas conversas transcritas abaixo ilustram a forma de aquisição das línguas e chamam também atenção para a necessidade de políticas linguísticas mais inclusivas que contemplem os imigrantes.

\footnotetext{
${ }^{6} \mathrm{O}$ termo taki-aki, atualmente em desuso entre os surinameses conforme Adamson e Smith (1995), é bastante difundido entre brasileiros e possui conotações negativas, podendo ser traduzido como "falação" ou "tagarelice'.
} 
H54: E o holandês não dá pra aprender na rua. Lhe garanto, senão a gente tava aí esperto. Tem que ter aula, não dá pra aprender assim de qualquer jeito. Ou você tem que ter um parceiro, um cônjuge. E esse cônjuge tem a didática, tem o dom da palavra... ele pode lhe ajudar, você pode se sair bem no holandês. Mas assim, aprendendo fragmentado, vendo televisão, não é possível (...) Tem que ter uma informação ali mesmo, técnica, pra aprender.

H20: O negócio é pra aprender (...) eu falo pouco (...) eu falo mais o sranantongo (...) Eu vim pra cá e não deu pra aprender nada. (...) Eu vim com 12 anos e deu pra eu vir pra escola, mas aí não dava pra eu aprender muito. Porque é muito brasileiro, daí na hora do recreio só fala português, conversa em português e aí não aprende nada (...) porque a professora não ensinava. Só fazia escrever no quadro (...) Aí eu escrevia letra por letra, porque eu não sabia nem ler. Tinha acabado de chegar.

E: E você terminou os estudos aqui? Você foi até aonde aqui?

H20: Não, eu parei. Eu entrei na terceira, fiz um ano e não quis mais, não (...) Não tava aprendendo nada. Eu aprendi só o taki-taki mesmo que meus primos me ensinavam. (...)

E: E você não chegou a fazer um cursinho particular, de reforço?

H20: Não, justamente por isso que eu não quis. Porque não tinha ninguém pra me ensinar. Meus primos em vez de me ensinar holandês tavam só me ensinando era taki-taki pra eu xingar os outros. Aí fica ruim.

E: Seus primos brasileiros tavam te ensinando taki-taki?

H20: Só me ensinaram besteira.

E: E o taki-taki assim que você chegou aqui, você já foi...

H20: Sim, e na escola também e com meus primos. Fui conversando e pegando amizade com os surinamenses na escola. Aí fui aprendendo. E hoje sei falar quase fluentemente, né.

Quanto aos usos funcionais que os falantes fazem das línguas contatantes, apresentamos o seguinte gráfico:

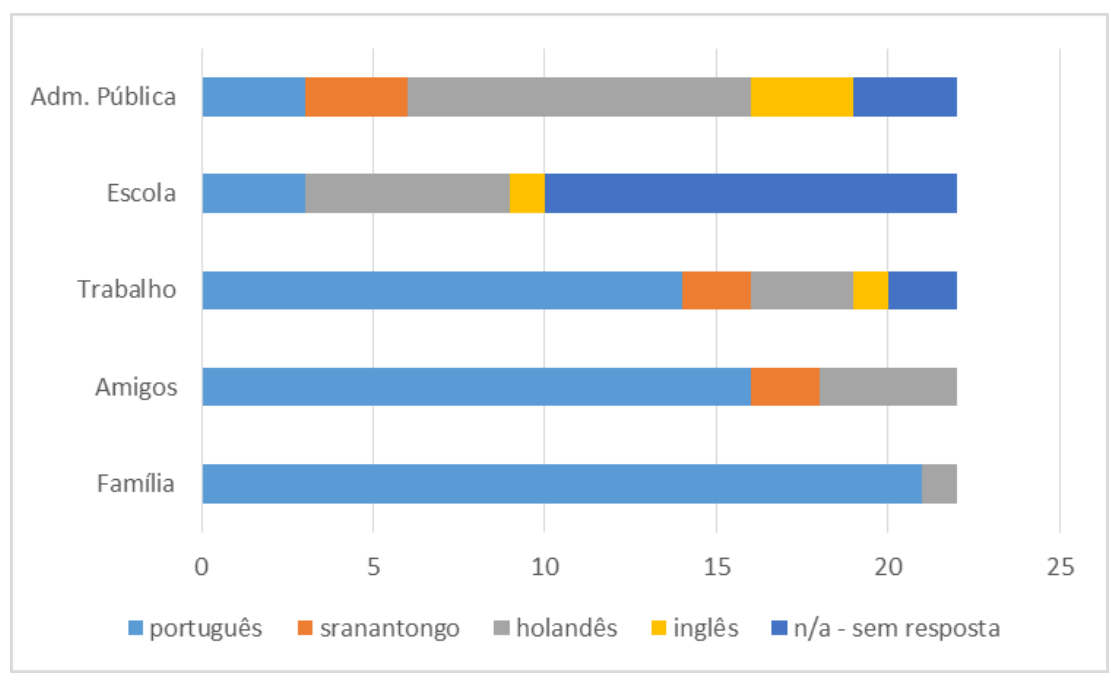

Grático 1: Relação de usos funcionais por ambiente comunicativo

Percebemos a forte presença do português nas vidas dos imigrantes. Como era de se esperar, considerando que a pesquisa abordou apenas a primeira geração de brasileiros, a L1 dos falantes é o idioma mais falado por quase a totalidade dos entrevistados no ambiente 
familiar, inclusive pela grande maioria das brasileiras casadas com surinameses, uma vez que elas se comunicam na língua com os filhos residentes no país e com suas famílias no Brasil. Em interações com amigos e vizinhos e até mesmo no ambiente profissional o português tem, para grande parte dos interlocutores, caráter igualmente predominante.

Declararam ser o holandês a língua mais usada entre amigos os informantes H33, M49, H19 e M45, os dois últimos já mencionados acima. As mulheres dessa relação tratam-se de indivíduos com nível superior completo, casadas com surinameses e que imigraram há pelo menos 10 anos. No caso dos homens, ambos concluíram ou estão cursando o ensino médio no país de destino. As jovens M15 e M20, também já descritas neste estudo, apesar de terem apontado o português como a língua mais usada no ambiente social devido à intensa interação com brasileiros, afirmaram comunicar-se exclusivamente em holandês com os amigos surinameses.

Já na comunicação junto a órgãos públicos surinameses, o português obviamente perde consideravelmente em relevância para a língua oficial do país. Os casos em que o português foi citado referem-se aos imigrantes que declararam recorrer a tradutores (cônjuges, tradutores oficiais, filhos, taxistas) em tais situações comunicativas.

Reforçamos aqui o ponto de vista exposto na seção 2 deste trabalho de que tais usos funcionais, assim como o plurilinguismo em si, são fenômenos fluidos que variam no decorrer das trajetórias dos falantes. De fato, muitos interlocutores encontraram dificuldades para definir qual era a língua mais usada em cada tipo de interação, como vemos nos depoimentos a seguir, que indicam ainda a ocorrência de situações de alternância de código linguístico e a presença de vários idiomas nos mesmos ambientes comunicativos:

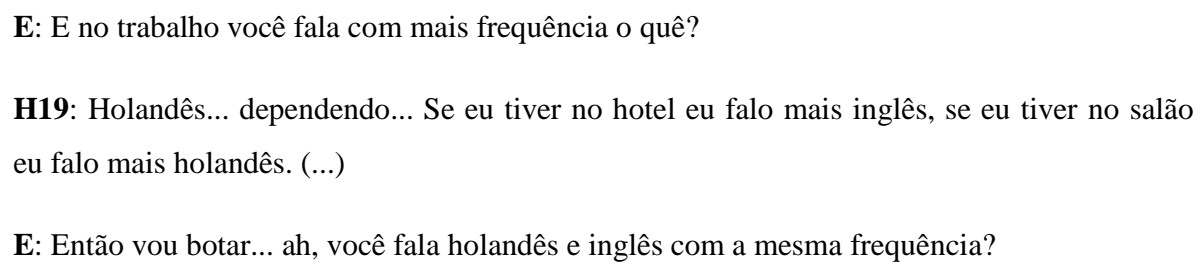

E: E com seus amigos, vizinhos, colegas de rua, você fala em que língua, na maioria das vezes?

M30: Ah, esses três idiomas aí... porque a variedade de amigos tem muito, né? 


\section{E: E o inglês, a senhora fala?}

M47: Olha, antigamente eu falava. Mas depois eu fui viver com ele (meu marido) e acabei esquecendo. Mas eu entendo. (...) E aqui em Suriname tem todos os filmes, novelas da Índia. Mas eles falam a língua do indiano, né... Só que tá tudo escrito no inglês. (...)

E: Com a família a senhora fala que língua?

M47: Lá em casa é tudo holandês. Só quando eu não entendo uma coisa, aí ele fala que é pra eu aprender. Ele não fala português comigo... Às vezes ele fala.

M41: Meus vizinhos são surinamenses que frequentam a minha casa. Eles falam holandês, falam holandês com meus filhos, falam um pouquinho de português porque já aprenderam com a gente aqui e eu falo com eles da mesma forma: taki-taki, misturando um pouquinho de holandês. Quando não, eu falo português mesmo e eles se viram pra entender.

Os entrevistados responderam também a perguntas relacionadas à frequência com que falavam cada uma das línguas. Com base nessas respostas, procurou-se entender melhor a natureza do plurilinguismo dos imigrantes, conforme demonstra o seguinte gráfico:

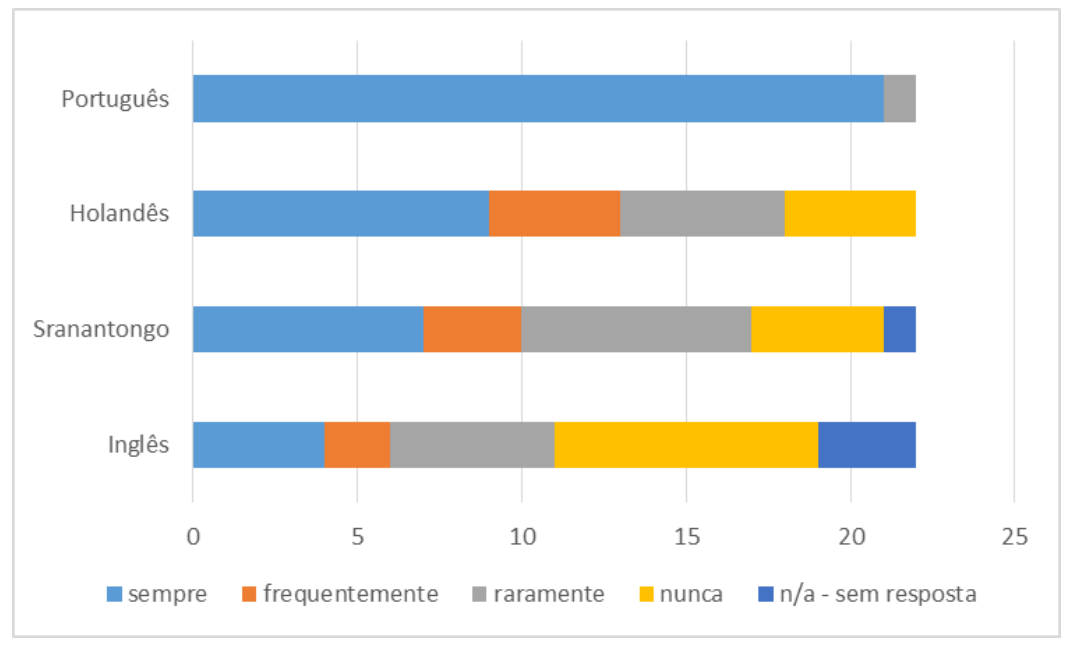

Gráfico 2: Frequência dos usos linguísticos

O português, mais uma vez, se destaca em relação às outras línguas. Apenas o falante H19, que, conforme pude evidenciar em diversas ocasiões ao longo de minha observação, se relaciona majoritariamente com surinameses e possui uma relação conflituosa com sua família, declarou usar a L1 raramente. Observo também que, dentre os 9 brasileiros que declararam usar o holandês sempre, encontram-se todos os 5 interlocutores que concluíram ou estão frequentando o ensino surinamês e 4 interlocutores com ensino superior concluído no Brasil. Analisando as frequências de uso do holandês e do sranantongo, percebemos que por uma parcela considerável dos entrevistados as duas línguas são usadas raras vezes ou nunca. 


\section{Considerações finais}

A análise dos usos linguísticos dos entrevistados e a revisão bibliográfica das recentes pesquisas conduzidas com surinameses nos permite enxergar de que maneira os imigrantes se inserem no cenário plurilíngue surinamês. Léglise \& Migge (2015) chamam atenção para a falta de dados sobre as práticas envolvendo o português brasileiro no Suriname, mas já observam que a presença da língua vem adicionando novas dimensões à realidade linguística do país.

Percebemos que os usos linguísticos dos jovens brasileiros entrevistados que imigraram quando crianças, frequentaram escolas locais e são plurilíngues parecem refletir a propensão para o uso ocasional do holandês também em situações informais que tem sido percebida entre crianças e adolescentes surinameses de Paramaribo, sinalizando mudanças na dinâmica diglóssica ideal, anteriormente aplicada sem grandes restrições para descrever a condição plurilíngue do país. No ambiente familiar, entretanto, o português segue sendo a língua mais utilizada pelos brasileiros, inclusive por aqueles casados com surinameses, o que indica um cenário favorável para a transmissão do idioma à próxima geração.

Apesar da maior simplicidade estrutural e das funções sociais do sranantongo, que continua permitindo a interação entre os diferentes grupos étnicos e, principalmente, com os indivíduos provenientes das novas ondas de imigração para o país, verificou-se que as brasileiras que dominam o holandês evitam a língua de contato, enquanto que aquelas sem competências suficientes na língua oficial se esforçam em pelo menos incorporar elementos dela em suas práticas em sranantongo. Tal conjuntura evidencia, conforme discutido por Perez (2015), uma adoção pelas falantes das ideologias linguísticas vigentes no Suriname que associam o idioma a uma vulgaridade não condizente com os ideais de feminilidade.

Analisando o perfil sociolinguístico dos entrevistados, vimos que a atualmente desatualizada definição do holandês como mercadoria de luxo, segundo sustentada por Campbell (1983), ainda se aplica à comunidade de fala do português do Brasil. A falta de políticas linguísticas inclusivas e a possibilidade relatada pelos informantes de se recorrer na comunicação diária ao sranantongo e até mesmo à L1 — dada a estrutura voltada a brasileiros presente no norte da capital e o número de surinameses falantes de português — mantêm o acesso à língua oficial restrito a uma pequena parcela de indivíduos escolarizados no país de 
destino e àqueles advindos de contextos socioculturais mais favorecidos e que aprenderam holandês como L3 ou L4.

Léglise \& Migge (2015) descrevem o sujeito plurilíngue como uma realidade inegável no Suriname atualmente, tendo sido essa asserção verificada também no caso do universo da amostragem aqui apresentada, composta por brasileiros originários de distintos contextos socioculturais. O plurilinguismo, como vimos na seção 2 e nos depoimentos de alguns informantes, é um fenômeno relativo condicionado pelo deslocamento geográfico dos indivíduos, pelas mudanças em suas dinâmicas familiares, profissionais e, em suma, pela própria natureza móvel desses falantes. Uma análise dos papéis sociais ocupados pelos imigrantes no país de destino e de seus repertórios linguísticos em holandês e/ou sranantongo foge ao escopo do presente trabalho, mas certamente permitiria enxergar com maior precisão as dimensões da condição plurilíngue desses sujeitos. Limitando-se aos dados colhidos em campo e aqui reproduzidos, é possível, contudo, fazer uma analogia à conclusão de Léglise \& Migge e afirmar que, de maneira geral, as línguas alvo — seja o holandês fluente de uma minoria de imigrantes crescidos no país, o sranantongo adquirido sem instrução formal e usado sem timidez em interações entre homens ou ainda as duas línguas usadas intercaladamente e por vezes de maneira rudimentar pelas mulheres como expressão de polidez - estão disponíveis e sendo usadas por praticamente todos os brasileiros de Paramaribo, ainda que certamente não da mesma maneira.

\section{REFERÊNCIAS}

ADAMSON, Lilian; SMITH, Norval. Sranan. In: ARENDS, Jacques; MUYSKEN, Pieter; SMITH, Norval (Eds.). Pidgins and creoles: an introduction. Amsterdam / Filadélfia: John Benjamins Publishing Company, 1995. p. 219-232

ALGEMEEN BUREAU VOOR DE STATISTIEK IN SURINAME. Bevolking. Disponível em http://www.statistics-suriname.org/index.php/statistieken/database/149-bevolking. Acesso em 6 ago. 2015.

BHATIA, Tej K.; RITCHIE, William C. Introduction. In: __. The handbook of bilingualism and multilingualism. Oxford: Wiley-Blackwell, 2013. p. xxi-xxiii

BLOOMFIELD, L. Language. Chicago: University of Chicago Press, 1984.

CAMPBELL, Hugo W. De nederlandse taal als luxe-waar op de Surinaamse markt? In: CHARRY, Eddy; KOEFOED, Geert; MUYSKEN, Pieter (Eds.). De talen van Suriname. Muiderberg: Coutinho, 1983. p. 188-200.

CARLIN, Eithne B.; ARENDS, Jacques. Atlas of the languages of Suriname. Leiden: KITLV Press, 2002. 
DEVONISH, Hubert. Language planning in pidgins and creoles. In: KOUWENBERG, Silvia; SINGLER, John V. The handbook of pidgin and creole studies. Oxford: Wiley-Blackwell, 2008. p. 615-636.

DIEPVEEN, Janneke; HÜNING, Matthias. The status of Dutch in post-colonial Suriname. In: SCHMIDT-BRÜCKEN, Daniel; SCHUSTER, Susanne; WIENBERG, Marina. Aspects of (post)colonial linguistics. Current perspectives and new approaches. Berlin: De Gruyter, 2016. p. 131-155.

EDWARDS, John. Bilingualism and multilingualism: some central concepts. In: BHATIA, Tej K.; RITCHIE, William C. The handbook of bilingualism and multilingualism. Oxford: Wiley-Blackwell, 2013. p. 5-25.

FERGUSON, Charles A. Diglossia (1959). In: GIGLIOLI, Pier-Paolo. (Org.) Language and social context: Selected readings. Baltimore: Penguin, 1972. p. 232-251.

FIERENS, L. Taalattitudes van Surinaamse jongeren ten opzichte van het Nederlands.

Katholieke Universiteit van Leuven, 2005. Disponível em:

http://www.scriptiebank.be/scriptie/taalattitudes-van-surinaamse-jongeren-tov-het-nederlands.

Acesso em: 03 abr. 2016

FISHMAN, Joshua A. Bilingualism with and without diglossia; diglossia with and without bilingualism. Journal of Social Issues, v. 23, n. 2, p. 29-38, 1967.

HÖFS, Carolina C. Yu kan vertrouw mi: você pode confiar. Dissertação (Mestrado em Antropologia Social). Instituto de Ciências Sociais, Universidade de Brasília, Brasília, 2006.

INDEX MUNDI. Suriname - School enrollment. Disponível em: http://www.indexmundi.com/facts/suriname/school-enrollment. Acesso em: 13 jan. 2017.

LÉGLISE, Isabelle; MIGGE, Bettina. Language practices and linguistic ideologies in Suriname: results from a school survey. In: CARLIN, Eithne B. et al. In and out of Suriname. Boston: Brill, 2015. p. 13-57.

MACKEY, William F. Bilingualism and multilingualism in North America. In: BHATIA, Tej K.; RITCHIE, William C. The handbook of bilingualism and multilingualism. Oxford: WileyBlackwell, 2013. p. 707-724.

PEREZ, Gabriel M.H. Estudo das representações linguísticas de imigrantes brasileiros no Suriname. In: SAPPIL, 6. 2015. Niterói. Anais... Niterói: Instituto de Letras da UFF - Estudos da Linguagem, p. 263-279, 2015.

Mooi misi no taki "taki-taki” / moça bonita não fala "taki-taki": gênero, práticas e representações linguísticas de imigrantes brasileiros no Suriname. Dissertação (Mestrado em Estudos da Linguagem). Instituto de Letras, Universidade Federal Fluminense, Niterói, 2017. ROMAINE, Suzanne. The bilingual speech community. In: . Bilingualism. Oxford: Blackwell, 1995. p. 23-77.

SAVEDRA, Mônica M.G.; Bilinguismo e bilingualidade: uma nova proposta conceitual. In: SAVEDRA, Mônica M.G; SALGADO, Ana C.P. (Org.). Sociolinguística no Brasil: uma contribuição dos estudos sobre línguas em/de contato. Rio de Janeiro: 7Letras, 2009. p. 121140.

THEIJE, Marjo de. Transnationalism in Surinam: Brazilian Migrants in Paramaribo. In: GOWRICHARN, Ruben. (Ed.). Caribbean Transnationalism: Migration, Pluralization, and Social Cohesion. Oxford: Lexington Books, 2006. p. 117-135.

TRIM, John L. et al. Quadro europeu comum de referência para as línguas: Aprendizagem, ensino, avaliação. Porto: Asa, 2001.

WEI, Li. Conceptual and methodological issues in Bilingualism and Multlilingualism Research. In: BHATIA, Tej K.; RITCHIE, William C. The handbook of bilingualism and multilingualism. Oxford: Wiley-Blackwell, 2013. p. 26-51 